journal of architecture, Volume 9 I Nomor 2 I Agustus I

2020

\title{
GEDUNG PEMBINAAN OLAHRAGA BULU TANGKIS TUNTUNG PANDANG TANAH LAUT
}

\author{
Nur Elma Dini \\ Program Studi Arsitektur Fakultas Teknik Universitas Lambung Mangkurat \\ Elmadinielma@gmail.com \\ Prima Widia Wastuty \\ Program Studi Arsitektur Fakultas Teknik Universitas Lambung Mangkurat \\ primawidiawastuty@ulm.ac.id
}

\begin{abstract}
ABSTRAK
Gedung Pembinaan Olahraga Bulu Tangkis Tuntung Pandang Tanah Laut merupakan sebuah tempat yang dirancang untuk memenuhi kebutuhan seorang atlet untuk menyalurkan bakat serta kemampuan yang dimiliki oleh individu maupun kelompok. Tingginya minat masyarakat dalam olahraga bulu tangkis ini tidak sebanding dengan prestasi yang seharusnya mampu diraih. Tujuan untuk memajukan prestasi olahraga bulu tangkis di Tanah Laut dapat dicapai dengan adanya pembinaan yang baik, fasilitas yang tersedia mampu menunjang kebutuhan bagi atlet, begitu juga dengan desain bangunan yang menarik akan mempengaruhi daya tarik masyarakat pada olahraga bulu tangkis sehingga membuka kesempatan yang lebih besar untuk mendapatkan pemain-pemain muda dalam melahirkan atlit-atlit daerah yang berprestasi. Pendekatan arsitektur ikonik pada bangunan, melalui karakter dari bulu tangkis yang elemen-elemennya tidak hanya mendukung fungsi dari bangunan gedung pembinaan olahraga tetapi juga memenuhi kriteria dari konsep arsitektur ikonik, yaitu memiliki skala bangunan yang besar, memiliki bentuk yang mudah dikenali, fungsional dan geometris. Sehingga eksterior bangunan mampu menyampaikan pesan dari bangunan sebagai gedung pembinaan olahraga bulu tangkis Tuntung Pandang Tanah Laut melalui bentuk-bentuk dan desain fasad dengan karakter bulu tangkis itu sendiri. Kemudian desain bangunan diharapkan mampu memberikan fasilitas yang bagus, bangunan yang menarik, dan mampu melahirkan atlit-atlit yang berprestasi.
\end{abstract}

Kata Kunci: Pembinaan, Bulu tangkis, Arsitektur Ikonik

\begin{abstract}
Badminton Tuntung Pandang Tanah Laut Sports Development Building is a place designed to meet the needs of an athlete to channel the talents and abilities possessed by individuals and groups. The high interest of the community in badminton is not comparable with the achievements that should be able to be achieved. The aim to advance the achievements of badminton in Tanah Laut can be achieved with good coaching, the available facilities are able to support the needs of athletes, as well as attractive building designs that will affect the attractiveness of the community in badminton sports thereby opening up greater opportunities for get young players in delivering regional athletes who excel. Iconic architectural approach to buildings, through the character of badminton whose elements in addition to supporting the function of building sports buildings as well as meeting the criteria of the iconic architectural concept, which has a magnificent building scale, has an attractive shape that is easily recognizable, functional and geometric, and has robustness through structural expression. So that the exterior of the building is able to convey the message of the building as a building for Badminton Tuntung Pandang Tanah Laut through the forms and design of the facade with badminton characteristics themselves. Then the building design
\end{abstract}


is expected to be able to provide good facilities, attractive buildings, and be able to give birth to athletes who excel.

Keywords: Guidance, Badminton, Architecture Iconic

\section{LATAR BELAKANG}

Pemerintah Indonesia ikut mendukung terwujudnya manusia yang sehat dengan menempatkan olahraga sebagai salah satu arah kebijakan pembangunan yang dituangkan dalam Tap MPR No. IV/ MPR/ 2004 (GBHN). Arah kebijakan itu berisi menumbuhkan budaya olahraga guna meningkatkan kualitas manusia sehingga memiliki tingkat kesehatan dan kebugaran yang cukup. Olahraga yang sebelumnya hanya sebagai aktivitas rekreasi semata, dengan tujuan untuk menjaga kesehatan tubuh sehingga bersemangat untuk melakukan kegiatan, seiring perkembangan jaman olahraga menjadi suatu wadah unjuk bakat dan kemampuan yang dimiliki para pelakunya dalam rangka meraih prestasi dibidang olahraga. Olahraga prestasi adalah olahraga yang mengembangkan potensi yang dimiliki oleh pelaku olahraga dengan membina secara terencana, berjenjang, dan berkelanjutan.

Pembinaan olahraga prestasi memberikan peranan menghasilkan atlit-atlet baru yang mampu bersaing untuk membentuk kualitas sumber daya manusia dalam rangka meningkatkan prestasi pada bidang olahraga di suatu kota, kabupaten maupun provinsi. Fasilitas yang menunjang kegiatan olahraga dapat mempermudah dan mendukung atlet-atlet yang memiliki potensi untuk berkembang lebih baik lagi. Berdasarkan Undang-Undang Republik Indonesia No.3 tahun 2005 tentang sistem keolahragaan nasional, disebutkan bahwa pemerintah, pemerintah daerah, dan masyarakat bertanggung jawab atas perencanaan, pemanfaatan, serta pengawasan sarana prasarana olahraga.

Tanah Laut merupakan salah satu Kabupaten di Provinsi Kalimantan Selatan, dengan Kota Pelaihari sebagai Ibukota Kabupaten Tanah Laut. Dalam bidang olahraga Tanah Laut memiliki fasilitas umum lapangan olahraga yang letaknya terpusat dengan berbagai macam cabang olahraga. Cabang olahraga yang aktif di Tanah Laut akan diseleksi dan di ikut sertakan pada Pekan Olahraga Provinsi (PORPROV) yang diadakan setiap 4 tahun sekali sebagai ajang kompetisi bergengsi bagi atlet guna meraih gelar dan prestasi bagi tiap-tiap daerah yang diwakilinya. Berikut KONI (Komisi Olahraga Nasional Indonesia) Kabupaten Tanah Laut mencatat data prestasi untuk tiap cabang olahraga yang diikutsertakan pada PORPROV Kalimantan Selatan.

Tabel 1 Data Jumlah Raihan Medali dalam Pertandingan PORPROV

\begin{tabular}{|c|c|c|c|c|c|}
\hline No & Cabor & $\begin{array}{l}20 \\
10\end{array}$ & $\begin{array}{l}20 \\
13\end{array}$ & $\begin{array}{l}20 \\
17\end{array}$ & $\begin{array}{l}\text { Jumlah } \\
\text { Medali }\end{array}$ \\
\hline 1 & Kempo & 13 & 19 & 20 & 52 \\
\hline 2 & Silat & 4 & 12 & 8 & 24 \\
\hline 3 & Renang & 3 & 11 & 12 & 26 \\
\hline 4 & Tinju & 10 & 5 & 9 & 24 \\
\hline 5 & Atletik & 5 & 7 & 5 & 17 \\
\hline 6 & $\begin{array}{l}\text { Panjat } \\
\text { Tebing }\end{array}$ & 6 & 13 & 8 & 27 \\
\hline 7 & Gulat & - & 6 & 8 & 14 \\
\hline 8 & Catur & 5 & 3 & 5 & 13 \\
\hline 9 & $\begin{array}{l}\text { Bulu } \\
\text { Tangkis }\end{array}$ & 0 & 0 & 0 & 0 \\
\hline
\end{tabular}




\begin{tabular}{|c|l|l|l|l|c|}
\hline 10 & $\begin{array}{l}\text { Bola voli } \\
\text { (Outdoor) }\end{array}$ & 1 & 1 & 2 & 4 \\
\hline 11 & $\begin{array}{l}\text { Bola } \\
\text { Basket }\end{array}$ & 0 & 1 & 1 & 2 \\
\hline
\end{tabular}

Sumber: Data Pertandingan PORPROV, KONI Kabupaten Tanah Laut

Dari data prestasi PORPROV yang telah disebutkan, sejak tahun 2010 cabang olahraga bulu tangkis sangat minim prestasi padahal olahraga bulu tangkis berkesempatan menyumbangkan medali dengan berbagai kategori yang dipertandingkan di dalamnya, faktanya adalah cabang olahraga yang tidak dapat meraih satupun medali hingga tiga kali PORPROV diadakan. Hal ini perlu diperhatikan mengingat di Tanah Laut terdapat fasilitas gedung olahraga bulu tangkis milik pemerintah daerah namun hal tersebut tidak menjamin kualitas dan kuantitas atlet bulu tangkis di Tanah Laut meningkat.

Faktor-faktor yang menghambat daya saing atlet bulu tangkis Tanah Laut adalah tidak adanya manajemen program pembinaan dan pengelolaan fasilitas dari pemerintah daerah yang tergabung dalam pengurus cabang olahraga bulu tangkis di Tanah Laut, begitu pula minat masyarakat yang hanya menjadikan olahraga bulutangkis sebagai olahraga rekreasi karena tidak ada wadah yang mengarahkan pada pembinaan yang jelas dari olahraga tersebut, serta fasilitas gedung olahraga yang ada tidak mampu memenuhi kebutuhan standar pembinaan atlet yang sudah ditetapkan, sehingga mengharuskan adanya penyelesaian untuk sejumlah permasalahan tersebut.

Perencanaan program pembinaan dengan baik untuk meningkatkan prestasi bulu tangkis tanpa didukung fasilitas penunjang yang baik dan sesuai menjadi salah satu faktor penghambat para atlit meningkatkan kemampuan fisik dan tekniknya, sehingga muncul suatu gagasan untuk menanggapi permasalahan yang ada dengan merencanakan gedung pembinaan olahraga bulu tangkis yang benar-benar membina dan mengembangkan potensi yang dimiliki pemain muda bulu tangkis Tanah Laut. Dalam upaya menjalankan suatu pembinaan yang lebih serius maka gedung pembinaan olahraga bulu tangkis yang akan dirancang melibatkan orang-orang yang memang mengerti dibidang olahraga bulu tangkis, berperan aktif dalam pembentukan pemain muda, dan fasilitas gedung pembinaan olahraga bulu tangkis yang dijalankan akan dikelola oleh pihak swasta dengan tujuan agar manajemen dan pembinaan atlet akan lebih terarah dan diperhatikan.

Rancangan gedung pembinaan olahraga bulu tangkis di Tanah Laut akan menampilkan karakter bulu tangkis untuk menarik perhatian masyarakat agar datang dan ikut serta berlatih di dalamnya dengan bentuk bangunan yang ikonik serta fasilitas yang sesuai standar Badminton World Federation (BWF). Program pembinaan pemain-pemain muda untuk Kabupaten Tanah Laut, akan menyediakan fasilitas penunjang pembinaan olahraga bulu tangkis untuk anak-anak, remaja, serta atlet bulu tangkis junior dan senior sehingga kegiatan pembinaan olahraga bulu tangkis di Kabupaten Tanah Laut diharapkan dapat melahirkan atlit-atlit daerah yang berprestasi dengan proses pembinaan yang jelas dan sistem keolahragaan yang tepat, dimana fasilitas tersebut dirancang dengan konsep bangunan yang menarik serta berintegrasi dengan GOR bulu tangkis yang telah ada.

\section{PERMASALAHAN}

Berdasarkan penjelasan yang telah disebutkan dalam latar belakang, maka permasalahan arsitektural yaitu bagaimana rancangan Gedung Pembinaan Olahraga Bulu Tangkis Tuntung Pandang Tanah Laut yang 
dapat menarik minat masyarakat untuk berpartisipasi pada program pembinaan pemain-pemain muda dalam melahirkan atlit-atlit daerah yang berprestasi dengan tampilan bangunan yang ikonik dan berintegrasi dengan GOR bulu tangkis yang ada?

\section{TINJAUAN PUSTAKA}

\section{A. Pengertian Olahraga Bulu Tangkis}

Menurut Subarjah (2000) "Bulu tangkis merupakan bentuk permainan bola kecil yang bersifat individual yang dapat dilakukan dengan cara melakukan satu orang melawan satu orang (single) atau dilakukan oleh dua orang melawan dua orang (double)". Kata bulu diambil dari bentuk atau wujud kok (shuttlecock) yang terbuat dari bulu angsa, sedangkan "tangkis" diambil dari kata dasar menangkis. Inti dari permainan bulu tangkis adalah menangkis pergerakan dari shuttlecock (bulu) tersebut.

\section{B. Pengertian Pembinaan}

Pembinaan adalah usaha atau tindakan yang dilakukan untuk menghasilkan sesuatu yang lebih baik. Mencapai suatu prestasi secara maksimal dan optimal perlu adanya pembinaan secara terprogram, terarah dan berkelanjutan serta didukung dengan faktor-faktor penunjang pembinaan. Daya melatih yang direncanakan pada program latihan tertulis secara sistematis sebagai arah kegiatan untuk mencapai tujuan pembinaan olahraga agar lebih efektif. Tercapainya prestasi adalah hasil dari persiapan atlet, berdasarkan program latihan yang telah direncanakan secara bertahap, obyektif, dan diterapkan secara berkelanjutan.

\section{Program Pembinaan Atlet}

\section{a) Program Latihan}

Program latihan yang diterapkan untuk latihan teknik adalah:

- Latihan stroke

- Latihan accuracy

- Latihan drilling

- Latihan circuit game

- Game

Program latihan fisik yang diterapkan adalah :

- Latihan dengan variasi bentuk circuit training

- Latihan variasi model trapping dengan berdurasi

- Skipping rope

- Lari jarak di bawah $5 \mathrm{~km}$ dan diatas 5 $\mathrm{km}$

- Latihan beban

- Latihan sprint

\section{b) Waktu Latihan}

Waktu dan jadwal latihan dari hari senin hingga hari kamis, untuk hari sabtu dan minggu fokus pada latihan fisik. Dalam pelaksanaan pembinaan, terbagi 3 kelompok, kelompok A (siap tanding), kelompok B (yang sudah punya dasar bermain), kelompok $\mathrm{C}$ (yang belajar dari awal). Pembagian kelompok tersebut berdasarkan kemampuan atlet dan calon atlet di dalam melakukan permainan bulu tangkis dan merupakan ketentuan dari pelatih di dalam pelaksanaanya. Berikut jadwal pelaksanaan latihan pembinaan:

Kelompok A : Senin - Kamis \& Sabtu Dimulai dari jam : 16.00-18.00 \& $(20.00-21.30)^{*}$

Kelompok B : Selasa - Kamis \& minggu Dimulai dari jam : 15.00-17.00

Kelompok C : Selasa - Kamis 
Dimulai dari jam : 13.00-15.00

Keterangan:

* Penambahan jadwal latihan jika atlet akan mengikuti pertandingan

\section{c) Program Ruang}

\section{Ruang Primer}

Ruang primer yaitu ruang-ruang utama yang wajib disediakan dalam perencanaan gedung pembinaan olahraga. Ruang primer merupakan ruang pengelola dan pengguna utama bangunan. yaitu:

- Ruang Pengelola

- Ruang Administrasi

- Area Lapangan Bulu Tangkis

- Ruang Fitness

- Ruang Edukasi Atlet (Serba guna)

\section{Ruang Sekunder}

Ruang sekunder yaitu ruang yang disediakan untuk mendukung kegiatan utama yang berlangsung di dalam bangunan utama. Ruangan ini meliputi:

- Ruang Ganti Atlit

- Toilet Umum

- Toilet Atlet

Toilet atlet terdiri dari, ruang mandi atau bilas serta toilet.

- Ruang Pelatih

- Ruang Medis Ruang medis berada dekat dengan area lapangan, ruang ganti serta ruang bilas.

- Ruang Pemanasan

- Ruang Keamanan

- Ruang Mesin dan Panel Ruang mesin diletakkan terpisah dengan bangunan utama untuk menghindari suara bising yang ditimbulkan. Ruang panel berdekatan dengan ruang mesin

- Gudang
- Ruang Staff Teknik

\section{Ruang Penunjang}

Ruang penunjang yaitu ruang pelengkap sebagai fasilitas tambahan untuk digunakan para pelaku kegiatan pada gedung pembinaan olahraga. Ruang-ruang tersebut meliputi:

- Tempat Parkir

Penyediaan ruang parkir untuk memenuhi fasilitas agar akses pengguna gedung pembinaan olahraga lebih mudah dan dekat dengan bangunan.

- Area Rekreasi

Sarana hiburan dapat berupa open space yang dilengkapi dengan fasilitas tambahan, seperti taman, jogging track, atau tempat duduk.

- Sport Station

Berupa fasilitas perbelanjaan yang disediakan bagi pengunjung atau atlet berupa alat dan barang untuk kegiatan olahraga.

- Kafetaria

Kafetaria sebagai ruang penunjang yang bertujuan memudahkan para pengguna gedung untuk makan di satu bangunan yang sama atau hanya sekedar bersantai.

- Musholla

Musholla sebagai tempat ibadah dimana pengguna gedung yang ingin beribadah tepat waktu tanpa harus keluar dari kawasan gedung pembinaan.

\section{TINJAUAN KONSEP}

\section{A. Pengertian Arsitektur Ikonik}

Arsitektur ikonik adalah suatu bangunan atau karya arsitektur yang dapat dijadikan penanda tempat di suatu lingkungan atau karya arsitektur yang menjadi tanda pada 
waktu maupun era tertentu. Bangunan ikonik memiliki kontribusi besar terhadap identifikasi citra dari kota atau tempat. Menurut Pawitro (2012) bangunan ikonik memiliki tiga ciri utama yaitu:

- Skala bangunan relatif besar

- Bentuk yang menarik dan atraktif, mudah diingat oleh orang banyak

- Memiliki unsur kekokohan bangunan yang tinggi atau berumur panjang.

\section{B. Karakteristik Bangunan Ikonik}

Desain gedung pembinaan olahraga bulu tangkis menggunakan pendekatan karakteristik dari bulu tangkis itu sendiri untuk mewakili bentuk-bentuk pada visual bangunan sehingga orang dapat mengetahui fungsi bangunan meski hanya melihat dari luar sehingga mudah diingat dan dikenali karena secara visual menarik perhatian orang sehingga menghasilkan bangunan yang ikonik.

Selain menampilkan bentuk dari karakter bangunan, gedung pembinaan olahraga bulu tangkis ini juga akan berintegrasi dengan gedung olahraga bulu tangkis yang telah ada sehingga desain mampu membangun karakter kawasan olahraga bulu tangkis yang kuat. Suatu bangunan ikonik dapat dikenali dari:

a) Bentuk yang mudah diingat

b) Bentukannya yang sangat rumit

c) Dari aktivitas di sekitar bangunan

d) Dari karakter yang ditampilkan bangunan

\section{PEMBAHASAN}

\section{A. Konsep Programatik}

Perancangan gedung pembinaan olahraga bulu tangkis Tuntung Pandang Tanah Laut menggunakan konsep iconic building untuk mencapai tujuan, yaitu bangunan yang mampu mengekspresikan fungsi bangunannya sehingga menjadi daya tarik bagi masyarakat umum saat melihatnya dalam upaya meningkatkan partisipasi masyarakat dalam pembinaan olahraga bulu tangkis sejak dini sebanyak-banyaknya. Konsep ini memperhatikan elemen-elemen karakteristik bulu tangkis itu sendiri melalui bentuk-bentuk yang ditampilkan pada bangunan.

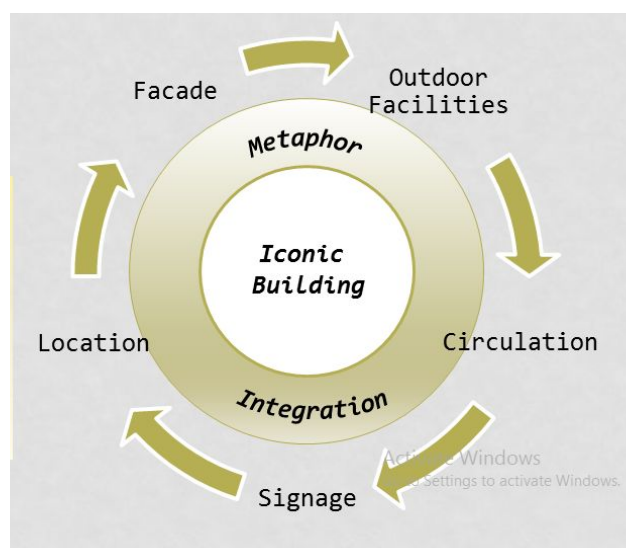

Gambar 1. Konsep Programatik

Berdasarkan pendekatan ikonik building terdapat elemen-elemen yang akan diaplikasikan pada visual bangunan dari bagian fasad, furniture hingga elemen pendukung pada kawasan pembinaan olahraga.

\section{B. Konsep Rancangan}

\section{a) Tata Massa}

Massa sebagai elemen site berupa vegetasi dan bangunan, keduanya sebagai unsur pembentuk ruang outdoor. Penyusunan massa ruang luar antara bangunan dan vegetasi akan dibentuk secara berimbang sehingga menciptakan ruang luar yang segar dan sehat. Kemudian massa dibentuk berdasarkan sifat dan organisasi ruang yang ditata untuk memudahkan pencapaian antar ruang oleh pengguna bangunan gedung pembinaan 
olahraga bulu tangkis berdasarkan aktivitas yang dilakukan serta kebutuhan ruang yang diperlukan.

Bangunan berupa massa tunggal dengan ketinggian 1 lantai, berbentuk persegi panjang yang berbeda level ketinggian atap disesuaikan dengan kebutuhannya, terdapat jalur sirkulasi antar ruang yang menghubungkan antar ruang utama dan ruang pengelola. Memaksimalkan luas ruang dengan bentuk persegi panjang yang disesuaikan dengan luas site dan keseimbangan antar bangunan dan ruang luarnya.

\section{b) Konsep Zoning Ruang Dalam}

Pembagian zona ruang dalam berdasarkan alur aktivitas antar pengguna bangunan gedung pembinaan olahraga bulu tangkis. Zona untuk ruang tamu dan ruang pendukung diakses melalui pintu utama gedung pembinaan olahraga. Area servis berada dekat dengan ruang utama dan ruang pengelola guna menunjang kegiatan utama. Ruang pendukung berupa musholla, ruang fitness, kafetaria dan sport shop berada pada massa 2 untuk memudahkan pengunjung yang hanya ingin mengakses fasilitas tersebut.

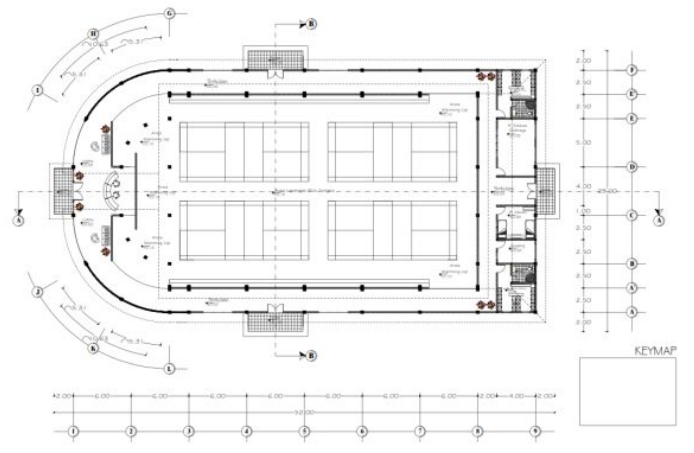

Gambar 2. Denah Bangunan Utama Pembinaan Olahraga Bulu Tangkis

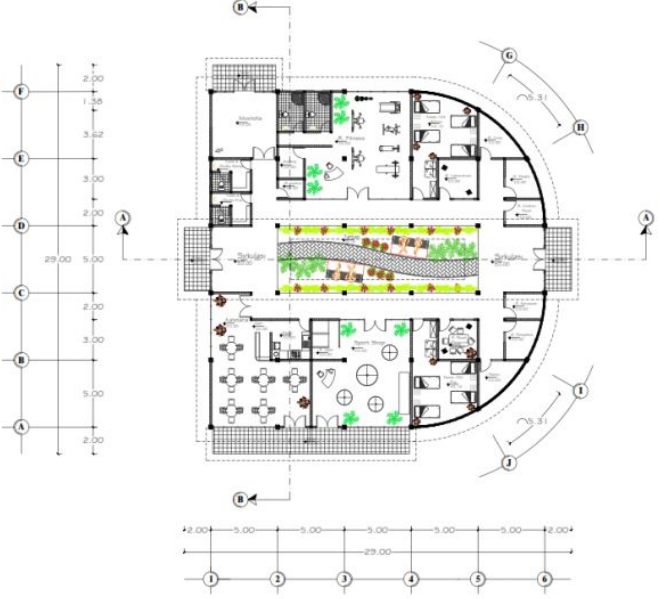

Gambar 3. Denah Bangunan Pengelola \& Publik

\section{c) Konsep Zoning Ruang Luar}

Konsep pembagian zona pada ruang luar berdasarkan fungsi, kegiatan, dan peruntukannya. Zona publik dimulai dari area parkir dan taman, kemudian lobby, sirkulasi serta ruang utama dan ruang pendukung. Zona semi publik berupa area pengelola, serta ruang-ruang yang digunakan khusus untuk para atlet. Pembagian zona untuk mempertegas fungsi aktivitas dengan jelas dan mengurangi kebisingan yang dihasilkan pada ruang utama untuk ruang-ruang yang memerlukan tingkat kebisingan yang rendah.

\section{d) Aspek Interior}

Desain pada interior bertujuan untuk menciptakan ruang dalam dengan elemen pendukungnya, Unsur-unsur pada aspek interior berupa bentuk, warna, tekstur, garis dan ruang. Elemen desain interior tersebut membantu dalam merencanakan rancangan interior yang fungsional bagi gedung pembinaan olahraga bulu tangkis sekaligus tampilan ruang yang menarik. 


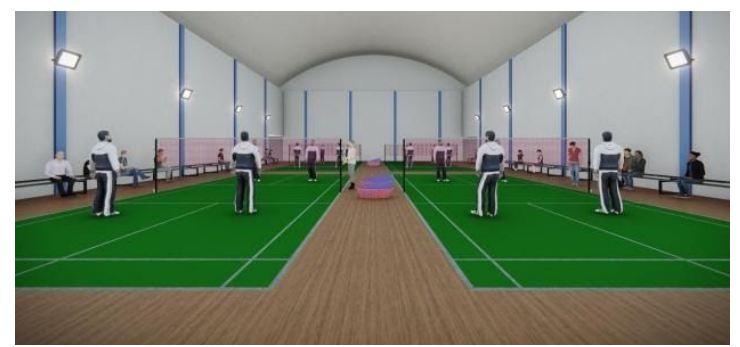

Gambar 4. Lapangan Badminton Indoor

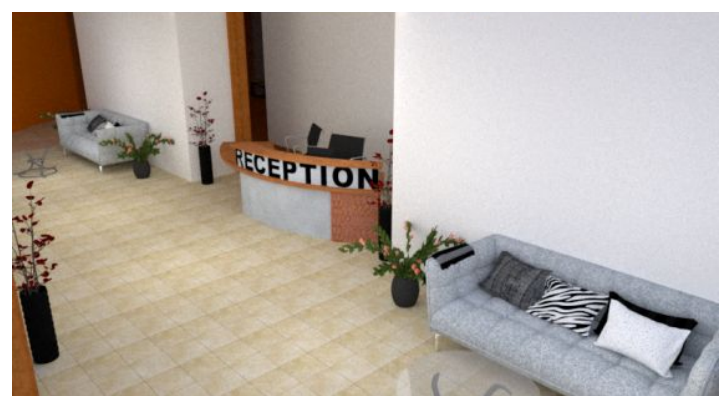

Gambar 5. Lobby

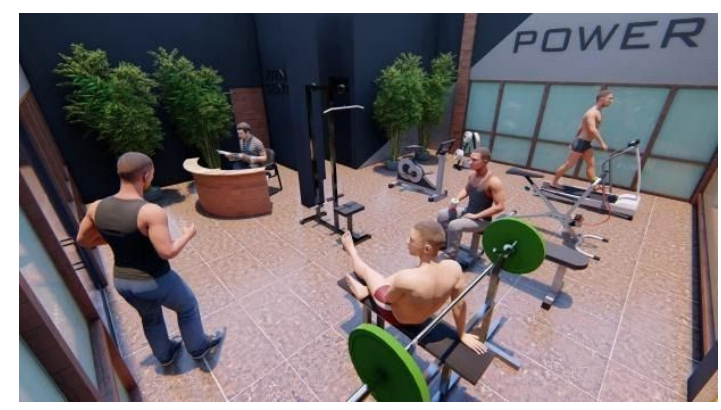

Gambar 6. Ruang Fitness

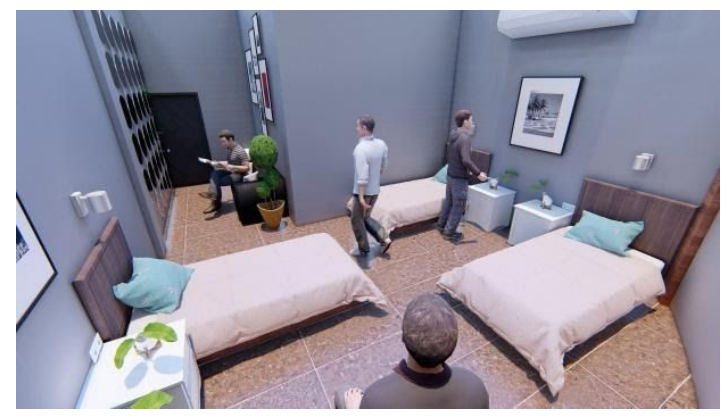

Gambar 7. Kamar Atlit

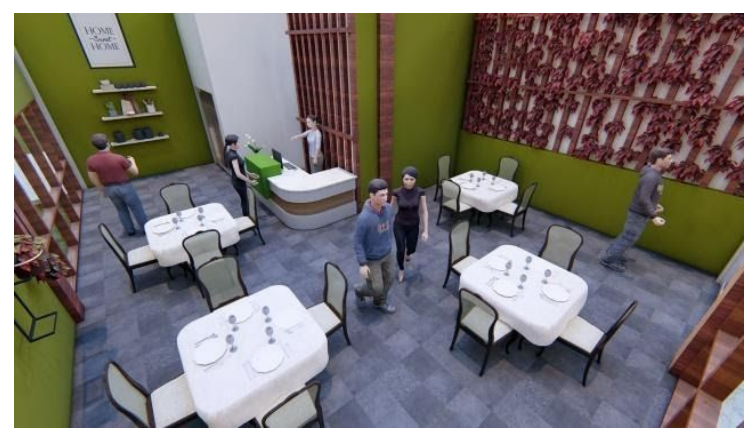

Gambar 8. Kafetaria

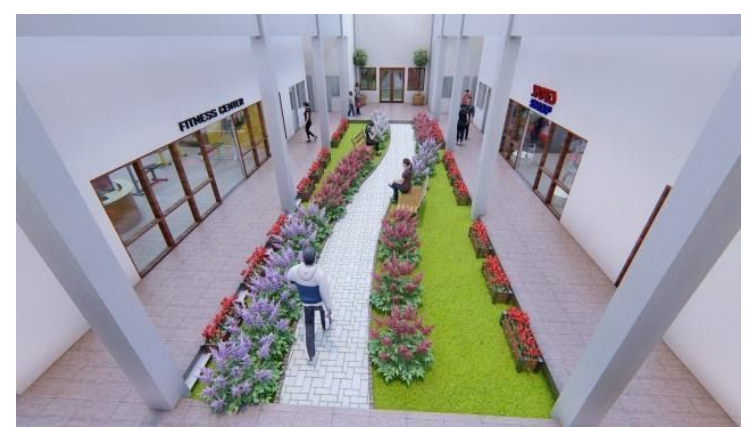

Gambar 9. Taman Indoor

\section{e) Aspek Eksterior}

Aspek eksterior merupakan segala elemen yang berada diluar bangunan. Ruang luar pada gedung pembinaan olahraga berupa parkir, taman, signage, serta jalur sirkulasi di dalam site. Elemen-elemen ruang luar dapat menerapkan karakteristik bulu tangkis sesuai dengan kebutuhan dan konsep.

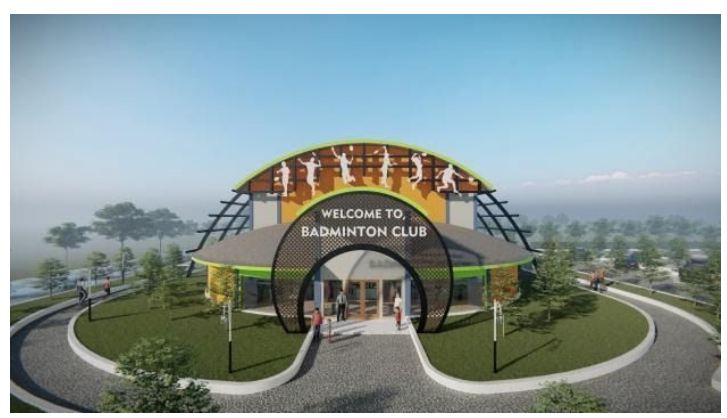

Gambar 10. Perspektif Eksterior Bangunan 


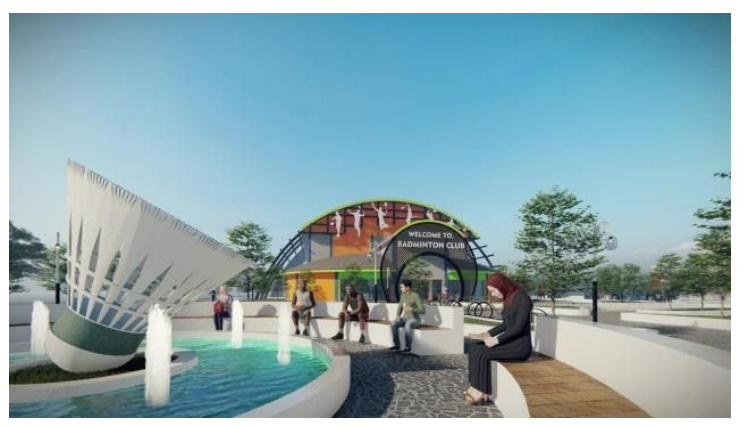

Gambar 11. Open Space

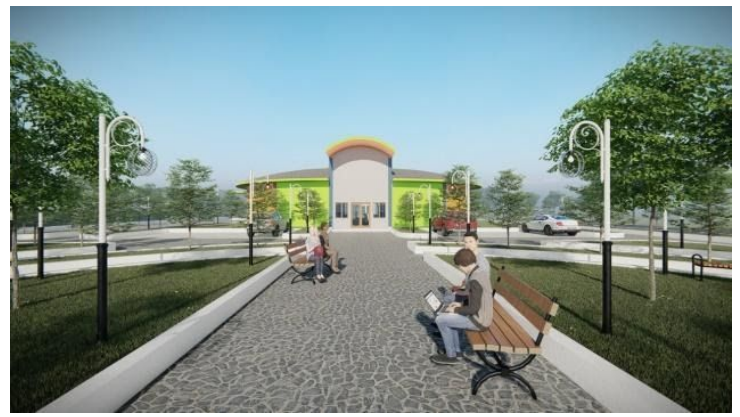

Gambar 12. Taman

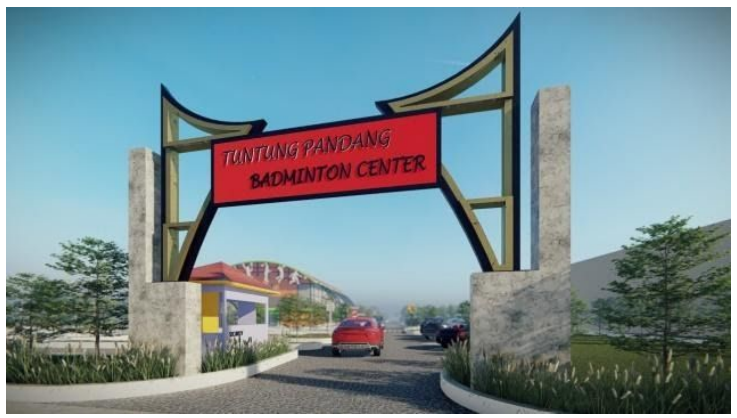

Gambar 13. Entrance

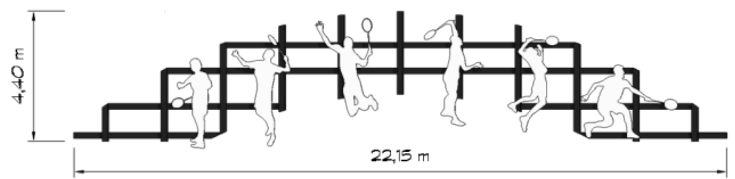

Gambar 14. Detail Fasade

\section{KESIMPULAN}

Gedung Pembinaan Olahraga Bulu Tangkis Tuntung Pandang Tanah Laut menggunakan metode pendekatan arsitektur ikonik yang elemen-elemennya tidak hanya mendukung fungsi bangunan gedung pembinaan olahraga tapi juga memenuhi kriteria dari konsep arsitektur ikonik, yaitu memiliki skala bangunan yang besar, memiliki visual bangunan yang mudah dikenali, fungsional dan geometris, sehingga menghasilkan konsep iconic building.

Mencapai tujuan dari "Iconic Building" rancangan bangunan gedung pembinaan olahraga bulu tangkis Tuntung Pandang Tanah Laut menerapkan karakteristik bentuk-bentuk dari bulu tangkis untuk menyampaikan pesan dari bangunan melalui fasade, elemen landscape, dan furniture bangunan.

Desain bangunan diharapkan mampu memberikan fasilitas yang berstandar, bangunan yang menarik, serta berintegrasi dengan gedung olahraga bulu tangkis yang sudah ada dengan tujuan mampu melahirkan atlit-atlit yang berprestasi untuk olahraga bulu tangkis di Tanah Laut.

\section{DAFTAR PUSTAKA}

Dep. P.U. (1994). Tata Cara Perencanaan Teknik Bangunan Gedung Olahraga. Retrieved from Dokumentips: https://dokumen.tips/documents/sni-03 $-3647-1994$

White, E. T. (1975). Concept SourceBook. Tucson: Architectural Media Ltd.

Tanggoro, D. (2004). Utilitas Bangunan. Jakarta: Universitas Indonesia.

U.U.R.I No.3 (2005). Sistem Keolahragaan Nasional. Retrieved from https://ngada.org/uu3-2005bt.htm 